\title{
Association between TPO Asn698Thr and Thr725Pro gene polymorphisms and serum anti-TPO levels in Iranian patients with subclinical hypothyroidism
}

\author{
Amirhosein Khoshi, ${ }^{1}$ Alireza Sirghani, ${ }^{2}$ Mehran Ghazisaeedi, ${ }^{3}$ Ali Zarei Mahmudabadi, ${ }^{2}$ \\ Amir Azimian ${ }^{4}$ \\ ${ }^{1}$ Department of Medical Biotechnology and Molecular Sciences, School of Medicine, North Khorasan University of \\ Medical Sciences, Bojnurd, IR; ' ${ }^{2}$ Department of Biochemistry, Baqiyatallah University of Medical Sciences, Tehran, IR; \\ ${ }^{3}$ Department of Internal Medicine, School of Medicine, North Khorasan University of Medical Sciences, Bojnurd, IR; \\ ${ }^{4}$ Department of Pathobiology and Laboratory Sciences, School of Medicine, North Khorasan University of Medical \\ Sciences, Bojnurd, IR Iran
}

\begin{abstract}
OBJECTIVE: Subclinical hypothyroidism (SCH) is defined as high levels of TSH in the presence of normal levels of serum FT4. Since thyroid peroxidase (TPO) plays a key role in thyroid hormone synthesis, variations in the TPO gene can change the enzyme structure and result in the production of anti-TPO antibodies. The aim of this study was to examine the relationship between the Asn698Thr (A2095C) and Thr725Pro (A2173C) polymorphisms of the TPO gene and anti-TPO levels in patients with SCH. DESIGN: In this study, 150 individuals (75 cases and 75 controls), aged 19-75 years, were selected randomly by a clinician. The thyroid function tests included were FT3, FT4, TSH and anti-TPO antibodies using ELISA. The TPO gene polymorphisms were examined by PCR-RFLP. RESULTS: Anti-TPO levels in the experimental group was significantly increased $(P=0.020)$. The $A 2095 C$ genotype frequency in the experimental and control groups were $37.3 \%$ vs $34.7 \%$ for the AA healthy genotype, $20 \%$ vs $46.7 \%$ for AC and $42.7 \%$ vs $18.6 \%$ for $\mathrm{CC}$, respectively $(\mathrm{P}=0.001)$. The $\mathrm{A} 2173 \mathrm{C}$ genotype frequency in the experimental and control groups were $22.6 \%$ vs $68 \%$ for healthy $\mathrm{AA}, 40 \%$ vs $25.3 \%$ for $\mathrm{AC}$ and $37.4 \%$ vs $6.7 \%$ for $C C$, respectively $(P<0.001)$. The increased anti-TPO antibodies were significantly associated with the $\mathrm{A2173C}$ polymorphism $(\mathrm{P}=\mathbf{0 . 0 3 5})$. The findings showed that the chance (odds ratio) of developing subclinical hypothyroidism in individuals who had $\mathrm{C}$ alleles was 1.5 and 5.6-fold higher than in individuals without these alleles in the $\mathrm{A2095C}$ and A2173C regions, respectively. CONCLUSIONS: Determination of anti-TPO antibody levels and exon 12 TPO gene polymorphisms in patients with SCH can be helpful for prediction of overt hypothyroidism.
\end{abstract}

Key words: Anti-TPO, Gene polymorphism, Subclinical hypothyroidism, Thyroid peroxidase

Amirhosein Khoshi, Clinical Biochemistry Ph.D., Department of Medical Biotechnology and Molecular Sciences, School of Medicine, North Khorasan University of Medical Sciences, Bojnurd, P.C.: 9417694735, IR Iran; Telefax: +98-58-32296764,

E-mail: ahkh83@gmail.com, ah.khoshi@nkums.ac.ir

Received: 13-01-2017, Accepted: 17-03-2017 


\section{INTRODUCTION}

Hypothyroidism may occur due to congenital thyroid abnormalities, iodine deficiency and autoimmune thyroid disease/Hashimoto's thyroiditis (AITD/ HT) in which antibodies against thyroid peroxidase (anti-TPO) serve as a clinical marker for the early detection of AITD/HT. ${ }^{1,2}$

Subclinical hypothyroidism ( $\mathrm{SCH}$ ) is defined as high serum thyrotropin or thyroid stimulating hormone (TSH) and normal levels of free thyroxine (FT4). ${ }^{3}$ Subclinical hypothyroidism is mild thyroid failure: it is a common condition with a prevalence of $3 \%$ to $8 \%$ in the population without known thyroid disease. The prevalence of SCH increases with age and is higher in women. ${ }^{4,5}$

Since serum TSH has a log-linear association with circulating thyroid hormone levels, measurement of TSH is the necessary test for diagnosis of mild thyroid failure when the peripheral thyroid hormone levels are within the normal laboratory range. ${ }^{3}$ About $80 \%$ of patients with $\mathrm{SCH}$ have a serum TSH of less than $10 \mathrm{mIU} / \mathrm{L}$, usually between $5-10 \mathrm{mIU} / \mathrm{L}$, as is typical of most SCH cases. ${ }^{6}$ It is estimated that patients with $\mathrm{SCH}$ have a high rate of progression toward clinically and also biochemically overt hypothyroidism, 2.6\% each year if anti-TPO antibodies are absent and $4.3 \%$ if they are present. However, some persons do not show progression, while some experience normalization. ${ }^{6,7}$

Thyroid peroxidase (TPO), a glycoprotein with enzyme activity in thyroid metabolism, plays a critical role in thyroid hormone synthesis, including thyroxin (T4) and 3-3'-5-triiodothyronine (T3), which have important roles in growth control, differentiation, regulation of metabolism and the physiological functioning of virtually all human tissues. ${ }^{8,9}$

The TPO gene on the short arm of chromosome 2 , locus 2 p25, consists of 17 exons. ${ }^{8,10}$ Some studies have suggested that mutations in the TPO gene with an autosomal recessive inheritance pattern are common causes of autoimmune thyroid diseases ${ }^{11,12}$ because some amino acid substitutions in the TPO protein may lead to recognition of this enzyme as a foreign antigen by the immune system and anti-TPO autoantibodies can be secreted against its actions. ${ }^{13,14}$

The prevalence of genetic single nucleotide poly- morphisms (SNPs) of the TPO gene differ according to race and/or between different populations, while TPO gene polymorphisms have been implicated in the pathogenic mechanism of hypothyroidism. ${ }^{15,16}$ One of the most common SNPs of the TPO gene which is reported in the Iranian population was identified in exon 12, this being related to increased levels of anti-TPO antibodies in patients with hypothyroidism. ${ }^{16}$

Previous studies have indicated that $T P O$ genetic polymorphisms may be associated with serum levels of anti-TPO antibodies. ${ }^{16-19}$ In addition, anti-TPO levels in $80 \%$ of patients with $\mathrm{SCH}$ are higher than in normal individuals. ${ }^{6}$

Based on the importance of preventing the manifestation of overt hypothyroidism and the high levels of serum anti-TPO antibodies that occur in most patients with $\mathrm{SCH}$, the aim of this study was to investigate the frequencies of some genetic polymorphisms of the TPO gene on exon 12, including A2095C (rs121908087) and $\mathrm{A} 2173 \mathrm{C}$ (rs732609), which are responsible for amino acid substitution in the TPO protein ats 698 Asn $\rightarrow$ Thr and $725 \mathrm{Thr} \rightarrow$ Pro, respectively; and compare these polymorphisms with anti-TPO levels in Iranian patients with subclinical hypothyroidism so as to explore the association between these polymorphic regions and anti-TPO antibody levels.

\section{MATERIALS AND METHODS}

\section{Study population}

A case-control study was performed in the city of Bojnurd in Northeast Iran between September 2015 and June 2016. Informed consent was obtained from each individual included in the study. The study protocol conforms to the ethical guidelines of the 1975 Declaration of Helsinki as reflected in a prior approval by the institution's human research committee of the North Khorasan University of Medical Sciences (ethic code: IR.nkums.REC.1394.142).

Eligible participants were 150 unrelated individuals including 75 cases with subclinical hypothyroidism and 75 healthy individuals without any complications as the control group, who were matched according to age (19-75y) and sex, without a history of thyroid dysfunction, who were admitted randomly to enroll in the present study and referred to the clinical labo- 
ratory of the Imam Reza Hospital of Bojnurd. Care was taken to ensure that the participants' mean ages in the two study groups were comparable

On the basis of clinical and laboratory investigations by a physician, 75 patients were selected as cases with subclinical hypothyroidism who had normal Free T3 and Free T4 levels and TSH levels higher than $5.2 \mathrm{mIU} / \mathrm{L}$, while 75 individuals with normal levels of Free T3, Free T4 and TSH were designated as the control group.

The structured questionnaire included age, sex, smoking habits, family history of thyroid diseases, history of neck surgery, history of drug usage, especially antidiabetic, lipid-lowering and antihypertensive drugs.

Patients with diabetes mellitus and/or with any liver, cardiovascular, rheumatologic, renal or thyroid diseases and also participants who had taken antihypertensive, antidiabetic, lipid-lowering and antithyroid drugs during 1 month before sampling were excluded from the study.

\section{Laboratory and molecular diagnosis}

The Free T3, Free T4, TSH and thyroid peroxidase antibody levels were measured via the Enzyme-linked immune absorbent assay (ELISA) method (Monobind, USA) using a plate reader (BioTek, USA).

For analysis of TPO gene polymorphisms, blood samples were collected in EDTA-coated tubes and stored at $-20^{\circ} \mathrm{C}$ until genomic DNA was extracted using the Proteinase K column method according to the protocol of the manufacturer (Sinaclon, Iran). After extraction, all DNA samples were measured by UV spectrophotometer and their purity was checked by A260/A280 ratio.

TPO A2095C (Asn $698 \mathrm{Thr}$ ) and A2173C (Thr 725 Pro) gene polymorphisms were determined by polymerase chain reaction (PCR) using premix tubes (Sinaclon, Iran) and followed by restriction fragment length polymorphism analysis (RFLP).

The PCR was used to amplify 209 bp for A2095C and $131 \mathrm{bp}$ fragments for the $\mathrm{A} 2173 \mathrm{C}$ polymorphism SNP in exon 12 of the TPO gene using the following oligonucleotide primers

F: 5'-ACTTCCTCCCCAGGGCTCGG -3' and R:
5'- GACTTGGAAGGCATCCATGG -3' for A2095C and F: 5'- TGCCCATGGATGCCTTCCAAG -3' and R: 5'- GCTCTCTGGGAAGCCACACT -3' for A2173C polymorphisms.

Polymerase chain reactions were carried out in a Veriti thermal cycler (Applied Biosystems, USA) in which DNA templates were denatured at $95^{\circ} \mathrm{C}$ for 5 minutes, amplification, consisting of 40 cycles at $95^{\circ} \mathrm{C}$ for 45 seconds, $58^{\circ} \mathrm{C}$ for 1 minute and $72^{\circ} \mathrm{C}$ for 45 seconds, with a final extension at $72^{\circ} \mathrm{C}$ for 5 minutes.

After that, the PCR products were subjected to restriction enzyme analysis by digestion at $65^{\circ} \mathrm{C}$ for $8 \mathrm{~h}$ with BseNI (BsrI) restriction endonuclease (ThermoFisher Scientific, USA). In the RFLP tests, each restriction endonuclease mixture (total volume $30 \mathrm{ul}$ ) contained $15 \mathrm{ul}$ amplified fragments, $12 \mathrm{ul}$ DNase free distilled water, 2 ul appropriate buffer and $1 \mathrm{ul}$ of BseNI restriction endonuclease (1 unit of restriction enzyme is the amount of enzyme required to digest $1 \mathrm{ug}$ of lambda DNA in $1 \mathrm{~h}$ at $65^{\circ} \mathrm{C}$ for BseNI). Restriction products were separated by electrophoresis on a 3\% agarose gel in TBE buffer and stained with DNA safe stain.

For confirmation of A2095C and A2173C SNPs in exon 12 of the TPO gene, the PCR products were investigated by sequencing and analyzed by MEGA 4.1 software.

\section{Statistical analyses}

SPSS software (version 20) was used for statistical analysis. Comparisons of demographic and thyroid panel tests between study groups were analyzed using the paired t-test. All data are expressed as mean $\pm \mathrm{SD}$. The frequencies of alleles and genotypes between the experimental and control groups were analyzed using the Chi-squared test. In addition, the correlation between genotype alleles with anti-TPO levels was examined by the Pearson correlation test. P values lower than 0.05 were considered statistically significant.

\section{RESULTS}

General characteristics and the thyroid function profile of participants are presented in Table 1. TSH means in the experimental and control groups were $8.8 \pm 0.36$ and $3.1 \pm 0.12$, respectively $(\mathrm{P}<0.001)$, but 
Table 1. General characteristic and thyroid function profile from participating individuals

\begin{tabular}{lccc}
\hline Parameters $^{\dagger}$ & $\begin{array}{c}\text { Case } \\
(\mathbf{n}=\mathbf{7 5})\end{array}$ & $\begin{array}{c}\text { Control } \\
(\mathbf{n = 7 5})\end{array}$ & P value \\
\hline Age (years) & $43.4 \pm 13$ & $43.2 \pm 12$ & 0.906 \\
Gender (female \%) & $96 \%$ & $96 \%$ & 0.981 \\
FT3 $(\mathrm{pmol} / \mathrm{L})^{\ddagger}$ & $4.48 \pm 0.042$ & $3.93 \pm 0.047$ & 0.207 \\
FT4 $(\mathrm{pmol} / \mathrm{L})^{\ddagger}$ & $19.3 \pm 0.033$ & $18.15 \pm 0.031$ & 0.233 \\
TSH $(\mu \mathrm{IU} / \mathrm{mL})^{\ddagger}$ & $8.8 \pm 0.36$ & $3.1 \pm 0.12$ & 0.0001 \\
Anti-TPO $(\mathrm{IU} / \mathrm{mL})^{\ddagger}$ & $169.3 \pm 26.7$ & $14.2 \pm 1.1$ & 0.02 \\
\hline
\end{tabular}

$\uparrow$ Data are expressed as arithmetic mean \pm SD.

$\$$ Thyroid function tests reference values: Free Triiodothyronine (FT3): 2.15 - 6.45; Free Thyroxin (FT4): 10.29 - 25.74; TSH: $0.4-5.2$; anti-TPO: $<39.3$.

in the FT3 and FT4 levels there were no significant differences between study groups. In addition, antiTPO levels in patients with subclinical hypothyroidism were higher than those in the control group ( $\mathrm{P}$ $=0.020)$. The power calculation of this study was estimated at around $80 \%$.

\section{TPO A2095C and A2173C genotypes determination}

As per the Hardy-Weinberg Equilibrium (HWE) law, there are two alleles of the TPO gene. For determination of the A2095C polymorphism, digested fragments of 92,79 and $38 \mathrm{bp}$ were detected in the healthy homozygotes for the A allele (genotype AA), while the digested fragments $117,92,79$ and 38 bp were detected in the heterozygotes (genotype $\mathrm{AC}$ ) and the digested fragments 117 and $92 \mathrm{bp}$ were detected in the homozygotes of the $\mathrm{C}$ allele (Figure 1). In order to identify the A2173C polymorphism, the undigested fragment of $131 \mathrm{bp}$ was detected in healthy homozygotes for the A allele (genotype AA), the digested fragments 68 and $63 \mathrm{bp}$ were detected in homozygotes for the $\mathrm{C}$ allele (genotype $\mathrm{CC}$ ) and both digested and undigested fragments 131, 69 and $62 \mathrm{bp}$ were detected in heterozygotes (genotype AC) (Figure 2).

Table 2 shows the TPO A2095C and A2173C genotype frequencies in the experimental and control groups. Frequencies of heterozygosity for the A/C allele 2095 in the experimental and control groups were $20 \%$ and $46.7 \%$, respectively; however, the frequencies

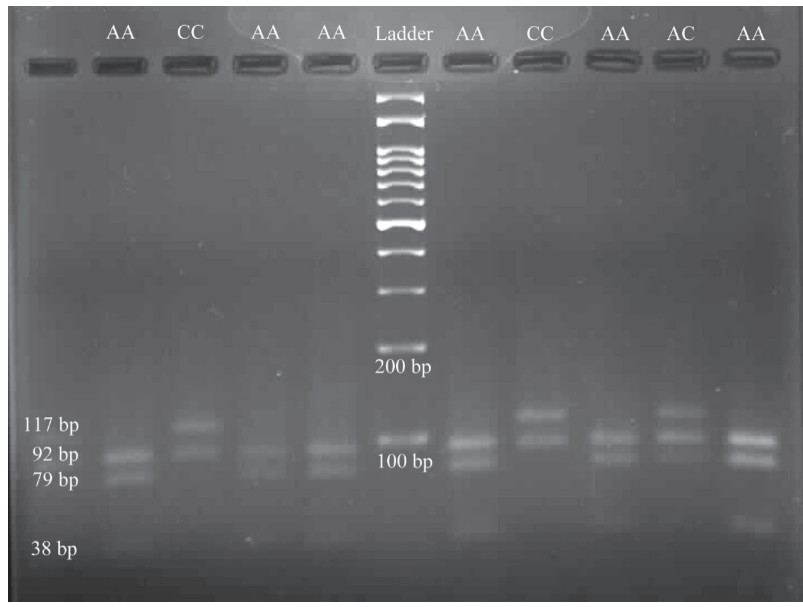

Figure 1. Electrophoretic bands of polynucleotide products after digestion with BseNI restriction endonuclease for determination of Asn 698 Thr (A2095C) polymorphism. A2095C genotypes include AA (normal), AC (polymorphism in one allele), and CC (polymorphism in two allele).

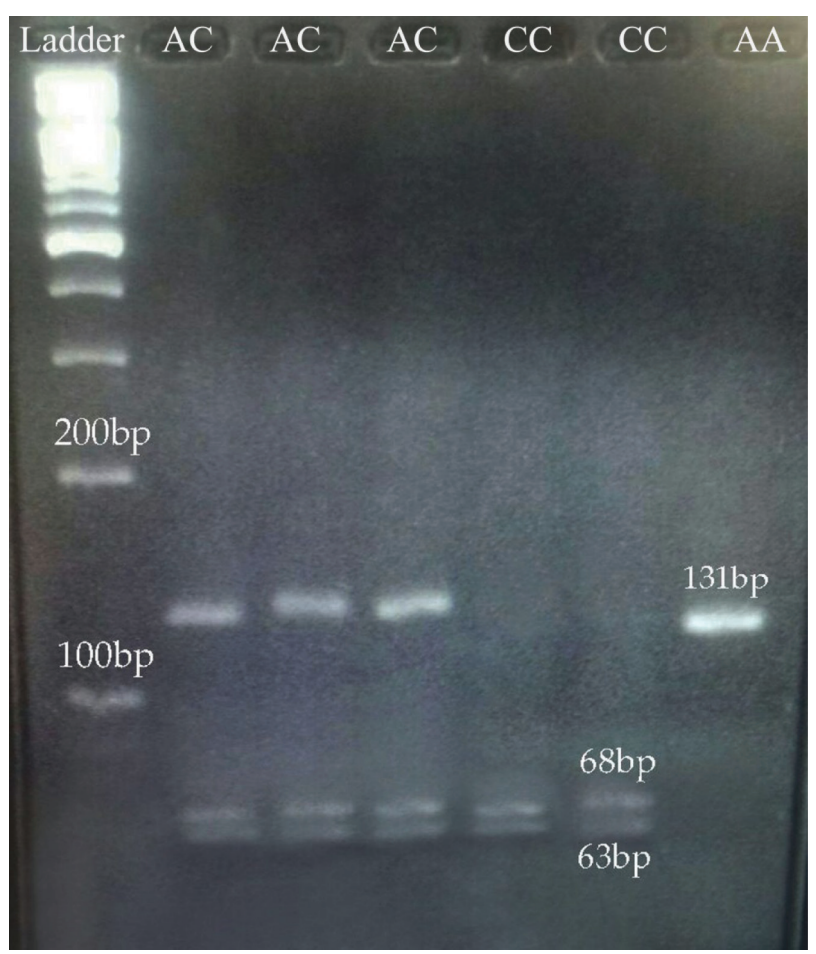

Figure 2. Electrophoretic bands of polynucleotide products after digestion with BseNI restriction endonuclease for determination of Thr 725 Pro (A2173C) polymorphism. A2173C genotypes include AA (normal), AC (polymorphism in one allele), and CC (polymorphism in two allele).

of the two allele polymorphisms (CC) in the experimental and control groups were $42.7 \%$ and $18.6 \%$, respectively $(\mathrm{P}=0.001)$ (Figure 3$)$. Furthermore, the 
Table 2. Comparison of TPO Asn698Thr (A2095C) and Thr725Pro (A2173C) genotype frequencies in study groups

\begin{tabular}{|c|c|c|c|c|c|c|c|c|c|c|c|c|c|c|}
\hline \multirow[b]{3}{*}{ Group } & \multicolumn{7}{|c|}{ A2095C polymorphism } & \multicolumn{7}{|c|}{ A2173C polymorphism } \\
\hline & \multicolumn{7}{|c|}{ Genotype data (\%) } & \multicolumn{7}{|c|}{ Genotype data (\%) } \\
\hline & $\mathbf{A A}$ & $\mathrm{AC}$ & $\mathrm{CC}$ & $\begin{array}{c}\text { A } \\
\text { allele }\end{array}$ & $\begin{array}{c}\mathrm{C} \\
\text { allele }\end{array}$ & $\begin{array}{c}P \\
\text { value }\end{array}$ & $\begin{array}{c}\text { OR } \\
\text { (CI 95\%) }\end{array}$ & AA & $\mathrm{AC}$ & $\mathrm{CC}$ & $\begin{array}{c}\mathrm{A} \\
\text { allele }\end{array}$ & $\begin{array}{c}\mathrm{C} \\
\text { allele }\end{array}$ & $\begin{array}{c}P \\
\text { value }\end{array}$ & $\begin{array}{c}\text { OR } \\
\text { (CI 95\%) }\end{array}$ \\
\hline $\begin{array}{l}\text { Case } \\
(\mathrm{SCH})\end{array}$ & $37.3 \%$ & $20 \%$ & $42.7 \%$ & $47.3 \%$ & $52.7 \%$ & & & $22.6 \%$ & $40 \%$ & $37.4 \%$ & $42.6 \%$ & $57.4 \%$ & & \\
\hline $\begin{array}{l}\text { Control } \\
\text { (Normal) }\end{array}$ & $34.7 \%$ & $46.7 \%$ & $18.6 \%$ & $58 \%$ & $42 \%$ & 0.001 & 1.5 & $68 \%$ & $25.3 \%$ & $6.7 \%$ & $80.7 \%$ & $19.3 \%$ & 0.0001 & 5.6 \\
\hline
\end{tabular}

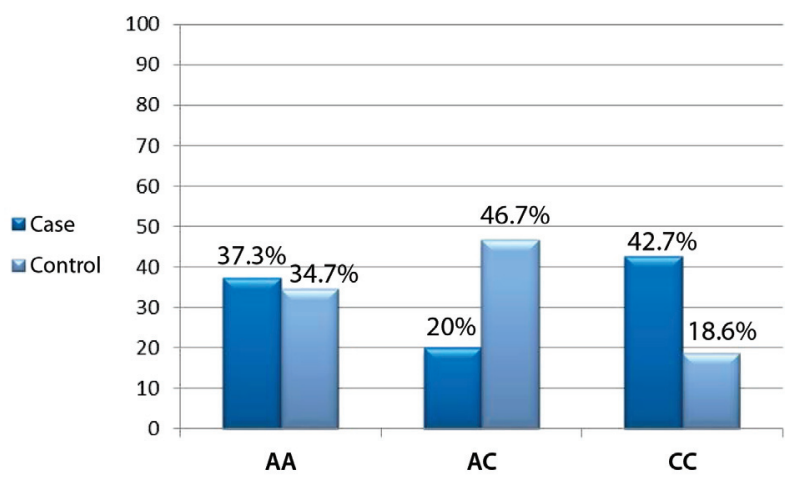

Figure 3. Frequencies of Asn $698 \mathrm{Thr}$ (A2095C) polymorphism in study groups. A2095C genotypes include AA (normal), AC (polymorphism in one allele), CC (polymorphism in two allele).

frequencies of heterozygosity for the $\mathrm{A} / \mathrm{C}$ allele 2173 in the experimental and control groups were $40 \%$ and $25.3 \%$, respectively, while the frequencies of the two allele polymorphisms (CC) in the experimental and control groups were $37.4 \%$ and $6.7 \%$, respectively $(\mathrm{P}<0.001)$ (Figure 4).

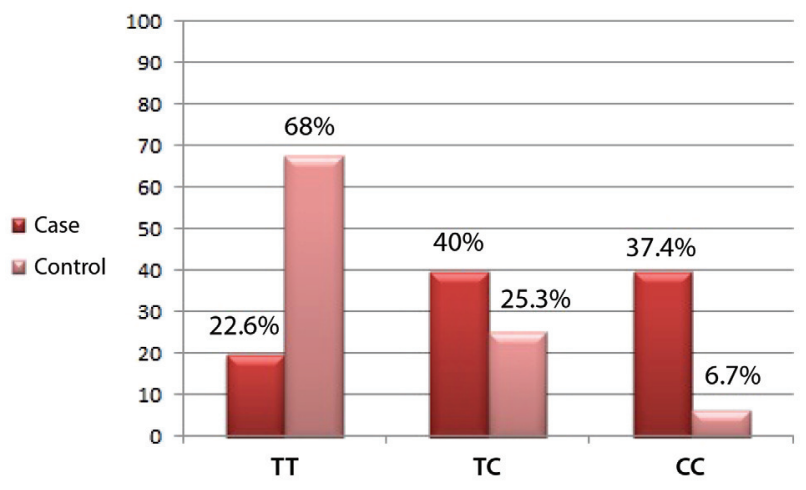

Figure 4. Frequencies of Thr 725 Pro (A2173C) polymorphism in case and control groups. A2173C genotypes include AA (normal), $\mathrm{AC}$ (polymorphism in one allele), $\mathrm{CC}$ (polymorphism in two allele).
Whenever there was an association between SNPs and anti-TPO antibody levels in the study groups there were no significant differences among serum anti-TPO levels and the three genotypes, namely AA, AC, and $\mathrm{CC}$ in the $\mathrm{A} 2095 \mathrm{C}$ polymorphism $(\mathrm{P}=0.086)$, while there were significant differences between anti-TPO levels and the three genotypes, namely AA, AC and $\mathrm{CC}$ in the $\mathrm{A} 2173 \mathrm{C}$ polymorphism region of the TPO gene $(\mathrm{P}=0.035)$ (Table 3$)$; these data regarding each SNP were calculated in the whole of the study groups. However, there was no significant correlation between other thyroid function tests in the genotypes of the TPO A2095C and A2173C polymorphic regions. The genotypes and allele frequencies of the A2095C and A2173C polymorphisms in the whole of the study population who had positive and negative anti-TPO antibody levels are depicted in Table 3.

The findings of the present study demonstrate that there is a significant correlation between the $\mathrm{C}$ allele of both the TPO A2095C and A2173C gene polymorphisms and patients with subclinical hypothyroidism ( $\mathrm{P}=0.001$ and $\mathrm{P}<0.001$, respectively). Investigation of the $\mathrm{A} 2095 \mathrm{C}$ and $\mathrm{A} 2173 \mathrm{C}$ polymorphisms in the experimental group revealed that the odds ratio (CI 95\%) in one or two alleles is 1.5 and 5.6 , respectively. Indeed, the probability ratio of the risk of subclinical hypothyroidism in patients who have $\mathrm{C}$ alleles in the $\mathrm{A} 2095 \mathrm{C}$ polymorphic region is 1.5 , but in the $\mathrm{A} 2173 \mathrm{C}$ region it is 5.6-fold higher than those without this allele. For example, if someone has the $\mathrm{A} 2173 \mathrm{C}$ polymorphism (i.e. $\mathrm{AC}$ or CC), the likelihood of his having $\mathrm{SCH}$ will be 5.6 times higher than in an individual who does not have this polymorphism. In addition, there is a significant association between high serum anti-TPO levels and subclinical hypothyroidism, this being substantiated 
Table 3. Association between TPO Asn698Thr (A2095C) and Thr725Pro (A2173C) gene polymorphisms and serum anti-TPO levels in study population

\begin{tabular}{|c|c|c|c|c|c|c|c|c|c|c|c|c|}
\hline \multirow[b]{3}{*}{ Anti TPO test } & \multicolumn{6}{|c|}{ A2095C polymorphism } & \multicolumn{6}{|c|}{ A2173C polymorphism } \\
\hline & \multicolumn{6}{|c|}{ Genotype data (\%) } & \multicolumn{6}{|c|}{ Genotype data (\%) } \\
\hline & AA & $\mathrm{AC}$ & $\mathrm{CC}$ & A allele & $\mathrm{C}$ allele & P value & AA & $\mathrm{AC}$ & $\mathrm{CC}$ & A allele & $\mathrm{C}$ allele & P value \\
\hline Anti TPO positive & $10 \%$ & $4.7 \%$ & $10.2 \%$ & $12.35 \%$ & $12.55 \%$ & \multirow{2}{*}{0.086} & $4 \%$ & $9.3 \%$ & $11.4 \%$ & $8.65 \%$ & 16.05 & \multirow{2}{*}{0.035} \\
\hline Anti TPO negative & $26 \%$ & $28.7 \%$ & $20.4 \%$ & $40.35 \%$ & $34.75 \%$ & & $40 \%$ & $23.3 \%$ & $12 \%$ & $51.65 \%$ & $23.65 \%$ & \\
\hline
\end{tabular}

in our study by the fact that $45.3 \%$ of the experimental individuals had elevated anti-TPO antibodies $(\mathrm{P}=$ 0.015). As expected, the odds ratio test showed that the risk of subclinical hypothyroidism in individuals with elevated serum anti-TPO was 19.9 times higher than in those with negative anti-TPO. According to the results of the Pearson correlation test, there was a significant relationship between anti-TPO and TSH levels in the case and control groups $(\mathrm{P}=0.001$ and $\mathrm{P}=0.006$, respectively).

\section{DISCUSSION}

The present study provides evidence of an association between A2095C (rs121908087) and A2173C (rs732609) genetic variations in the TPO gene with anti-TPO levels in patients who have subclinical hypothyroidism $(\mathrm{SCH})$. The results showed that these polymorphic regions have a significant correlation with subclinical hypothyroidism. In addition, as expected, the serum anti-TPO titer had increased significantly in the patient group, especially in those who have the $\mathrm{C}$ allele in the A2173C polymorphic region. Furthermore, we detected the presence of amino acid substitutions, such as Asn698Thr for A2095C and Thr725Pro for the $\mathrm{A} 2173 \mathrm{C}$ polymorphism, on performing bioinformatics studies.

Autoimmune thyroid disease (AITD) is thought to arise from a combination of genetic and environmental factors. ${ }^{17}$ Since the protein structure of thyroid peroxidase is related to genetic variations in the $T P O$ gene, TPO appears to play a critical role in thyroid hormone synthesis; however, genetic variations may lead to changes in its structure, thus the TPO enzyme is recognized as a foreign body and antibodies are produced against it. ${ }^{1}$ Hashimoto's thyroiditis (HT), an autoimmune disease in which the thyroid gland is gradually destroyed by lymphocyte invasion and antibody-mediated immune processes, is the most common cause of hypothyroidism ${ }^{6,17}$ and may occur as a result of subclinical hypothyroidism. ${ }^{16}$

Since the TPO enzyme structure and/or its activity is defective in autoimmune thyroid disease, for the first time the hypothesis is being proposed that genetic variations of the TPO gene may contribute to the occurrence of these diseases. ${ }^{13,14}$

Based on the results of the present study, in the presence of the C allele of A2173C SNP, anti-TPO antibody levels would increase in patients with subclinical hypothyroidism, although we did not observe any correlation between increased anti-TPO levels and the $\mathrm{C}$ allele of A2095C.

Because of the high prevalence of subclinical hypothyroidism and its associated metabolic risk factors such as hyperlipidemia, the American Thyroid Association recommends screening tests by measurement of serum TSH after the age of 35 at 5-year intervals. ${ }^{20}$

To date, several studies have found evidence of the association of TPO gene polymorphisms with anti-TPO levels in patients with hypothyroidism; however, the genetic variations in the TPO gene and their correlation with anti-TPO antibodies levels have not been investigated in patients with subclinical hypothyroidism who do not have overt hypothyroidism and its symptoms.

In line with studies which indicated that $T P O$ gene variations such as polymorphisms are associated with anti-TPO levels ${ }^{17-19}$, as well as with some studies in patients with overt hypothyroidism in the Tehran population, ${ }^{1,16}$ the present study also indicates the association of genetic characterization of the TPO gene with anti-TPO levels. However, the novelty of our study was to investigate exon 12 TPO gene polymorphisms in patients with subclinical hypo- 
thyroidism who do not have overt hypothyroidism; furthermore, we have demonstrated the relationship between the Asn698Thr polymorphism and subclinical hypothyroidism for the first time.

Schultheiss et al. have studied subjects of Caucasian ancestry in three independent prospective populations including the Atherosclerosis Risk In Communities Study, the Study of Health in Pomerania and the Study of Health in Pomerania (SHIP-TREND). They have identified four novel genetic loci and confirmed five known loci associated with anti-TPO antibody levels. A Genetic Risk Score (GRS) based on index SNPs in these nine loci (including RERE, MAGI3, TPO, KALRN, HCP5, HLA-DOB, HLA-DPB1, BACH2, $A T X N 2)$ revealed strong and graded associations not only with anti-TPO levels and positivity but also with TSH and FT4 concentrations $(\mathrm{P}<0.001)$, as well as with the clinical entities subclinical and overt hypothyroidism and goiter. Furthermore, they have shown that in comparison with individuals in the lowest GRS quartile, those in the highest quartile had 1.80-fold higher odds of subclinical hypothyroidism and 1.89-fold higher odds of overt hypothyroidism. ${ }^{17}$ This study points to the importance of the nine genetic variations, among them in particular the TPO gene SNP rs11675434, in patients with autoimmune hypothyroidism.

Faam et al have reported that $T P O$ genetic variations of exon 11 and exon 12, the polymorphisms of T1936C and A2257C, but not of T2229C, are significantly associated with high levels of serum anti-TPO antibodies in patients with hypothyroidism; however, these associations were attenuated after adjustment for sex and age. ${ }^{1}$ In the present study, there was no relationship between patient's age and either TPO A2095C or A2173C polymorphisms. Our Primer-BLAST investigation revealed that some electrophoretic bands and primer sequences in the study of Faam et al. ${ }^{1}$ were not matched to the TPO gene, thus we cannot cite and compare our findings with this study.

Bikker et al reported that a genetic variation in exon 10 of the TPO gene has a significant effect on the enzyme activity of TPO. ${ }^{21}$ Brčić et al. have reported that two SNPs (rs1077462, rs11675434) are associated with anti-TPO antibodies levels in patients with Hashimoto's thyroiditis. They suggested that genetic variations in or near the TPO gene are associated with HT. ${ }^{2}$ Balmiki et al. have demonstrated that two TPO gene polymorphisms, namely Thr725Pro (rs732609) and Asp666Asp (rs1126797), had a significant correlation with those of Indian patients with hypothyroidism. ${ }^{15}$ Similarly, we were also able to show the significant relationship between the Thr725Pro (A2173C) gene polymorphism of TPO and patients who had elevated serum TSH, but not FT3 and FT4, who were identified as having subclinical hypothyroidism. Hedayati et al. have investigated the effect of two polymorphisms of the $T P O$ gene, namely $\mathrm{T} 1193 \mathrm{G}$ in exon 8 and T2145C in exon 12, and their correlation with anti-TPO serum levels in Iranian patients with hypothyroidism. ${ }^{16}$ They reported that $\mathrm{T} 1193 \mathrm{G}$ was not polymorphic and that there was no association between this SNP and serum anti-TPO levels, whereas the presence of the $\mathrm{C}$ allele in the T2145C polymorphism was correlated with increased levels of serum anti-TPO antibodies and was also significantly associated with serum anti-Tg levels, ${ }^{16}$ this confirmed by the fact that $71.2 \%$ of hypothyroid patients had the $\mathrm{C}$ allele in this polymorphic region. In addition, the frequency of the $\mathrm{C}$ allele, particularly of the $\mathrm{CC}$ genotype, was more closely related to serum anti-TPO levels (OR: 9.2). In the present study, the $\mathrm{C}$ allele of both $\mathrm{A} 2095 \mathrm{C}$ and A2173C polymorphic regions, especially of the CC genotype, was also associated with patients with subclinical hypothyroidism (OR: 1.5 and 5.6 for A2095C and $\mathrm{A} 2173 \mathrm{C}$, respectively). It is necessary to note that we could not find the T2145C polymorphism as reported in the study by Hedayati et al ${ }^{16}$ given that their results had an explicit bias, particularly in primer design and the use of the BsrI enzyme digestion site, hence the sequence in the 2145 nucleotide position is CC드, which cannot be recognized by this restriction enzyme. BseNI (BsrI) can recognize the ACTGGN sequence and digest the PCR product at the $\mathrm{A} \downarrow$ position; this digestion type was observed in the $\mathrm{A} 2173 \mathrm{C}$ and $\mathrm{A} 2095 \mathrm{C}$ polymorphic regions. Indeed, both polymorphic regions were changed to $\mathrm{C}$ according to our sequencing data.

Our study had some potential limitations. First, we acknowledge that the sample size of the present study was relatively small and that the frequency of 
TPO genetic polymorphisms should be confirmed by investigation of a larger population. In addition, most of the patients diagnosed as $\mathrm{SCH}$ were female. Furthermore, in concordance with previous studies which have focused on exon 12 of the TPO gene, we chose two candidate gene polymorphisms that can create missense mutations; certainly, additional studies on more polymorphisms of the TPO gene will provide further insights.

In summary, the findings of the present study demonstrate that $45.3 \%$ of patients with subclinical hypothyroidism had positive anti-TPO antibodies, while our statistical analyses have shown that the probability risk of disease in individuals with positive anti-TPO antibodies is 19.9 times higher than those with normal levels of serum anti-TPO. Since there is a correlation between the $\mathrm{C}$ allele of the $\mathrm{A} 2173 \mathrm{C}$ polymorphism and anti-TPO levels, it could be hypothesized that the presence of the $\mathrm{C}$ allele at 2173 nucleotide in exon 12 of the TPO gene could have an important role in the change of the thyroid peroxidase protein structure, thus it may produce autoantibodies against this protein. Therefore, on the basis of the demonstrated association of TPO gene polymorphisms with racial differences in the incidence of autoimmune thyroiditis, we suggest that the evaluation of the gene polymorphisms of TPO exon 12 and the measurement of anti-TPO antibodies levels is likely to be helpful in Iranian patients with subclinical hypothyroidism and that, with time, therapeutic intervention may be able to prevent the incidence of overt hypothyroidism in these patients.

\section{ACKNOWLEDGMENT}

This study was supported by the Research Center of the North Khorasan University of Medical Sciences; funding under grant No: 94/60/678.

\section{DISCLOSURE STATEMENT}

The authors have nothing to disclose.

\section{REFERENCES}

1. Faam B, Daneshpour MS, Azizi F, Salehi M, Hedayati M, 2012 Association between TPO gene polymorphisms and Anti-TPO level in Tehranian population: TLGS.
Gene 498: 116-119.

2. Brčić L, Barić A, Gračan S, et al, 2016 Association of established thyroid peroxidase autoantibody (TPOAb) genetic variants with Hashimoto's thyroiditis. Autoimmunity 1-6.

3. Cooper DS, 2001 Subclinical hypothyroidism. New England Journal of Medicine 345: 260-265.

4. Hollowell JG, Staehling NW, Flanders WD, et al, 2002 Serum TSH, T4, and thyroid antibodies in the United States population (1988 to 1994): National Health and Nutrition Examination Survey (NHANES III). J Clin Endocrinol Metab 87: 489-499.

5. Karmisholt J, Andersen S, Laurberg P, 2008 Variation in thyroid function tests in patients with stable untreated subclinical hypothyroidism. Thyroid 18: 303-308.

6. Fatourechi, V, 2009 Subclinical hypothyroidism: an update for primary care physicians. Mayo Clin Proc 84: 65-71.

7. Vanderpump MPJ, Tunbrldge WMG, French J, et al, 1995 The incidence of thyroid disorders in the community: a twenty-year follow-up of the Whickham Survey. Clin endocrinol 43: 55-68.

8. Kimura S, Hong YS, Kotani T, Ohtaki S, Kikkawa F, 1989 Structure of the human thyroid peroxidase gene: comparison and relationship to the human myeloperoxidase gene. Biochemistry 28: 4481-4489.

9. Andersen S, Pedersen KM, Bruun NH, Laurberg P, 2002 Narrow individual variations in serum T4 and T3 in normal subjects: a clue to the understanding of subclinical thyroid disease. J Clin Endocrinol Metab 87: 1068-1072.

10. Endo Y, Onogi S, Umeki K, et al, 1995 Regional localization of the gene for thyroid peroxidase to human chromosome 2p25 and mouse chromosome 12C. Genomics 25: 760-761.

11. Fugazzola L, Cerutti N, Mannavola D, et al, 2003 Monoallelic expression of mutant thyroid peroxidase allele causing total iodide organification defect. J Clin Endocrinol Metab 88: 3264-3271.

12. Fugazzola L, Mannavola D, Vigone MC, et al, 2005 Total iodide organification defect: clinical and molecular characterization of an Italian family. Thyroid 15: 1085-1088.

13. Czarnocka B, Ruf J, Ferrand M, Carayon P, Lissitzky S, 1985 Purification of the human thyroid peroxidase and its identification as the microsomal antigen involved in autoimmune thyroid diseases. FEBS letters 190: 147-152.

14. Portmann L, Hamda N, Heinrich G, Degroo LJ, 1985 Anti-thyroid peroxidase antibody in patients with autoimmune thyroid disease: possible identity with antimicrosomal antibody. J Clin Endocrinol Metab 61: 1001-1003.

15. Balmiki N, Bankura B, Guria S, et al, 2014 Genetic analysis of thyroid peroxidase (TPO) gene in patients whose hypothyroidism was found in adulthood in West Bengal, India. Endoc J1 61: 289-296. 
16. Hedayati M, Jahromi MS, Yeganeh MZ, et al, 2010 Association between serum level of anti-TPO titer and polymorphisms G1193/C Exon 8 and C2145/T Exon 12 of thyroid peroxidase gene in an Iranian population. Int J Endocrinol Metab 8: 64-67.

17. Schultheiss UT, Teumer A, Medici M, et al, 2015 A genetic risk score for thyroid peroxidase antibodies associates with clinical thyroid disease in community-based populations. J Clin Endocrinol Metab 100:E799-807.

18. Abramowicz MJ, Targovnik HM, Varela V, et al, 1992 Identification of a mutation in the coding sequence of the human thyroid peroxidase gene causing congenital goiter. J Clin Invest 90: 1200.

19. Kotani T, Umeki K, Kawano JI, et al, 2003 Partial iodide organification defect caused by a novel mutation of the thyroid peroxidase gene in three siblings. Clin Endocrinol 59: 198-206.

20. Ladenson PW, Singer PA, Ain KB, et al, 2000 American Thyroid Association guidelines for detection of thyroid dysfunction. Arch Int Med 160: 1573-1575.

21. Bikker H, Baas F, de Vijlder JJ, 1997 Molecular Analysis of Mutated Thyroid Peroxidase Detected in Patients with Total Iodide Organification Defects 1. J Clin Endocrinol Metab 82: 649-653. 